\title{
Carbon-11 Acetate
}

National Cancer Institute

\section{Source}

National Cancer Institute. Carbon-11 Acetate. NCI Thesaurus. Code C38712.

The acetate salt of the radioisotope carbon-11. Although the mechanism is unclear, carbon-11 acetate preferentially accumulates in tumor tissue, serving as a tracer for imaging tumors with positron emission tomography (PET). (NCI04) 